\title{
RAINHAS DO CLUBE E MUSAS DO SAMBA-ROCK: RAÇA GEENERO NA SOCIABILIDADE NEGRA
}

QUEENS OF THE CLUB AND MUSES OF SAMBA-ROCK: RACE AND GENDER IN BLACK SOCIABILITY

\section{Karina Almeida de Sousa}

Docente assistente II no curso de Licenciatura em Ciências Sociais da Universidade Federal do Tocantins (UFT), coordenadora do Grupo de Estudos e Pesquisas sobre Raça e Temas Educacionais (GERTE). Atuou como coordenadora de área no Programa Institucional de Bolsa de Iniciação à Docência (PIBID/Sociologia) e membro do Centro de Referência em Cidadania e Direitos Humanos (CRDH). É pós-graduanda (nível doutoramento) no Programa de Pós-graduação em Sociologia da Universidade Federal de São Carlos (UFSCar), mestra em Sociologia pela mesma instituição e com especialização em Educação e Patrimônio Cultural e Artístico pela Universidade de Brasília (UnB). 


\section{RESUMO}

Raça e gênero articulam-se em diversos contextos; neste artigo a autora foca no cenário dos clubes sociais negros e bailes black/samba-rock da capital e do interior do estado de São Paulo, a partir de dados etnográficos, entrevistas e coleta de materiais audiovisuais. As restrições ao acesso da população negra à comunidade mais ampla a partir da pós-abolição são parte do cenário de emergência dos clubes sociais negros, bem como dos bailes, nesse sentido esses espaços surgem e desenvolvem-se buscando garantir atividades recreativas, culturais ou beneficentes para um grupo específico. Nos clubes sociais atividades recreativas como bailes de gala, bailes de debutantes e desfiles de miss são tomadas como expressão da intersecção entre gênero e raça na construção de uma forma específica de sociabilidade. Atualmente os clubes, bem como os eventos realizados em suas dependências, sofreram uma drástica redução, passando a ser substituídos pelos bailes de samba-rock. Aqui, os dados etnográficos nos apresentam elementos suficientes para analisar as continuidades e as rupturas entre performances e estereótipos de gênero e raça, principalmente quando refletimos sobre o papel social desenvolvido pelas mulheres e as performatividades esperas/desejadas. O artigo investiga, portanto, as negociações que os espaços em questão apresentam no que se refere às representações sobre o feminino a partir da intersecção entre raça e gênero.

PALAVRAS-CHAVE: sociabilidade; clubes sociais negros; bailes; raça; gênero.

\section{ABSTRACT}

Race and gender are articulated in different contexts, in this article we will focus on the scenario of Black Social Clubs and Black/Samba-Rock Balls in the capital and in the interior of the state of São Paulo, based on ethnographic data, interviews and collection of audiovisual materials. Restrictions on the access of the black population to the wider society after the post-abolition period are part of the emergency scenario of black social clubs, as well as of the balls, in this sense these spaces appear and develop in order to guarantee recreational, cultural or cultural activities. beneficiaries for a specific group. In social clubs, recreational activities such as gala balls, debutante balls and miss won parades are taken as an expression of the intersection between gender and race in the construction of a specific form of sociability. Currently, the clubs, as well as the events held inside, have suffered a drastic reduction, being replaced by samba-rock balls. Here, the ethnographic data present us with sufficient elements to analyze the continuities and the ruptures between performances and stereotypes of gender and race, especially when we reflect on the social role developed by women and the expected / desired performance. The article investigates, therefore, the negotiations that the spaces in question present regarding the representations about the feminine from the intersection between race and gender.

KEYWORDS: sociability; black social clubs; black/samba-rock balls; race; gender. 


\section{Unir para festejar, unir para lutar}

Quilombos, irmandades religiosas, associações, sociedades e agremiações; blocos carnavalescos; escolas de samba; jornais; grupos teatrais; coletivos e bailes são alguns exemplos de espaços construídos por e para a comunidade negra. Um olhar direcionado à história dos movimentos de luta e resistência da população negra, particularmente nas Américas, aponta para a centralidade da arte, da música e da dança como elemento de construção de uma grande parte desses espaços. Nesse sentido, ressalta-se ainda o spiritual, o jazz e o soul no Estados Unidos; ${ }^{1}$ o candombe no Uruguai; o jongo, o maracatu, o samba e suas derivações ${ }^{2}$ como expressões artísticas inerentemente vinculadas à luta e à resistência das populações negras nas Américas.

Enquanto o processo social e político de construção do Estado-nação primou por políticas de desagregação, desterritorialização e marginalização dos elementos capazes de contribuir para a identificação dos sujeitos da diáspora, ${ }^{3}$ a música e a dança, mesmo quando atravessadas pelos interesses mercadológicos, indicam dinâmicas próprias das comunidades afrodescendentes. Ou seja, os grupos descendentes da diáspora africana no Brasil se organizaram de modo complexo e versátil. O que implica afirmar que as sociabilidades negras se caracterizam por sua multiplicidade, versatilidade e dinamicidade. Nessa perspectiva, o samba e algumas de suas variações, ou ainda o sambarock, o samba de gafieira, a umbigada e o maracatu representam processos históricos em que a cultura expressiva negra tem produzido sociabilidades específicas.

As expressões musicais e artísticas desenvolvidas pela população negra possibilitam a reflexão acerca de sociabilidades que apontam para uma sobreposição do modelo da comunidade lógico-racional-ocidental e indicam o estabelecimento de uma rede de solidariedade junto ao modelo de coesão fundado em elementos de identificação coletivos. Disso decorre a afirmação de que a dança e a música, como elementos de identificação

\footnotetext{
${ }^{1}$ O jazz e o soul, são algumas das vocalizações melódicas trazidas da África através da diáspora, ambos entoados pelos escravos durante infindáveis rotinas de trabalho. Influenciou profundamente o desenvolvimento do rock (rhythm and blues), mas foi inviabilizada a partir dos interesses do mercado musical e dos conflitos raciais entre o norte e o sul dos Estados Unidos.

${ }^{2}$ De acordo com o Dicionário da História Social do Samba (LOPES, 2015), pode-se elencar as seguintes variações de samba: samba batucado; samba de breque; samba de caboclo; samba de chave; samba de embolada; samba enredo; samba de gafieira; samba de matuto; samba de morro; samba de primeira; samba de raiz; samba de roda; samba de rua; samba de salão; samba de terreiro; samba de velho; samba do criolo doido; samba duro; samba esquema novo; samba moderno; samba sincopado; sambacanção; samba-choro; samba-exaltação; samba-jazz; sambalanço; samba-lenço; samba-reggae; samba-rock; samba-roda; samba-soul; samba de angola; samba joia/pagode romântico; samba trançado.

${ }^{3}$ Diáspora, na qualidade de deslocamentos étnicos, culturais e territoriais transnacionais, coloca em questionamento a noção dos Estados-nação como correspondentes a um espaço homogêneo. A partir da compreensão de que existem nações dentro de um mesmo Estado, e mesmo comunidades que não reconhecem o Estado, a diáspora amplia as reflexões para além das fronteiras nacionais traçadas pelo Estado-nação. Em larga medida essa nova condição de reflexão não apenas questiona a "homogeneidade" linguística, política e cultural, mas por meio de elementos culturais, religiosos e mesmo étnicos torna possível que se estabeleçam continuidades para além das fronteiras nacionais. Segundo Gusmão e Simson (1989, p. 219), a diáspora "envolveria processos de circulação de um povo, vivenciando mobilidade geográfica, induzida ou não, possibilidade contraditória para o estabelecimento de 'raízes'. [...] Assim, ações criativas dos povos como sujeitos de sua história, isto é, ações mobilizadoras em seu próprio proveito, formas e contextos de luta em mutação; transformações psicoculturais e ideológicas; redes sociais e dinâmicas institucionais constituem-se em exemplos de experiência histórica compartilhada".
} 
coletivos das populações negras, podem ser localizadas nas mais diversificadas configurações sociais e históricas desses grupos.

As análises apresentadas irão reiterar as distintas organizações e os padrões culturais da comunidade negra em um contexto urbano, tal qual grande parte das pesquisas em Ciências Sociais focada na construção de uma análise a partir da região Sudeste, considerando o significado do gênero em interseção com a raça na análise dos clubes sociais negros e nos bailes black ${ }^{4} /$ samba-rock, $^{5}$ charme $^{6}$ e nostalgia.

Clubes e bailes são considerados para efeito deste estudo espaços distintos para brancos e negros, logo é proposta uma reflexão sobre a existência de uma sociabilidade inerentemente não branca, considerando sua existência, suas características e como ela se realiza, partindo da compreensão de que a música e a dança são formas de expressão inerentes e transversais de identificação e trocas das comunidades transatlânticas negras, buscando compreender como as dinâmicas postas pela a intersecção entre gênero e raça se organizam e quais efeitos podem ser investigados.

Paul Gilroy, na obra There ain't no black in the Union Jack: the cultural politics of race and nation (2002), propõe uma vasta compreensão sobre o racismo e sua condição histórica, identificando duas questões que atravessam diferentes momentos e espaços. Na primeira questão o negro é visto como um problema, enquanto na segunda é visto como vítima. $O$ autor estabelece um link entre a linguagem, as políticas antirracistas e as políticas de classe. Trata-se de uma articulação da representação de classe sobreposta às categorias que têm produzido e reproduzido os significados de raça, portanto Gilroy (2002) destaca

\footnotetext{
${ }^{4}$ De acordo com João Batista Felix (2000, p. 10), todo os bailes eram chamados de baile funk em referência ao estilo musical norte-americano que vigorava na época. No Rio de Janeiro essa denominação permaneceu, enquanto em São Paulo foi sendo alterada à medida que se alteraram as referências e os estilos musicais adotados pelos artistas, passando a ser chamados de bailes soul e, na sequência, de bailes black. Atualmente os bailes mantêm as referências aos estilos musicais, sendo hoje conhecidos como bailes black, bailes chame ou bailes samba-rock. O que não exclui chamadas que unem as três denominações, levando-nos à compreensão de que estas são complementares e representam dinâmicas similares.

${ }^{5}$ Segundo Oliveira (2008), existem versões sobre o surgimento do termo samba-rock por conta da ordem com que as músicas eram executadas nos bailes, alternando-se ora uma canção de rock ora um samba. Assim, primeiramente se falou em "rocksamba", e até mesmo se utilizava apenas o termo "rock", para só depois se afirmar o nome "samba-rock". Expressões como "É bom esse rock?" ou "Você sabe dançar esse rock?", eram frequentemente utilizadas, mesmo que estivesse tocando no baile alguma música brasileira ou até mesmo um jazz norte-americano.

${ }^{6}$ O charme é um estilo musica inspirado na black music norte-americana, nascido da mistura do hip hop e do soul. Nos bailes de charme nota-se a predominância de músicas internacionais, com grandes nomes da cultura negra norte-americana. É uma dança coletiva em que todo o grupo desenvolve passos idênticos ao ritmo da música. O Baile Charme do Viaduto de Madureira, por exemplo, acontece há 25 anos. Nos bailes black de São Paulo (capital e interior) o charme ocupa os intervalos entre grupos musicais ou DJs.

${ }^{7}$ A pesquisa recém-defendida por Pedro D’Allevedo debruça-se sobre a análise dos bailes nostalgia da cidade de São Paulo. Por sua particularidade, tomamos a definição de D'Allevedo $(2017$, p. 10) para fins desta pesquisa: “[O baile nostalgia] é uma forma de encontro dançante animada através de sons e ritmos oriundos de distintos gêneros musicais, os quais são propagados de forma mesclada e intercalada, obedecendo ao critério relacionado à execução do estilo de dança a que remetem. Alguns desses ritmos são reconhecidos pela denominação Samba-rock, enquanto outros, provenientes da Black Music norte-americana, são tidos por balanços ou melodias. Essa forma de festividade, desde a origem, é produzida e frequentada exclusivamente por afrodescendentes das camadas populares, em grande medida provenientes das regiões menos abastadas da metrópole em questão". Aqui cabe apenas um adendo quanto ao público. Durante minhas observações sobre o Clube Aristocrata, renomado clube da elite negra paulistana, houve a divulgação de um baile mensal chamado Baile dos 30, o qual leva o título de nostalgia por seus realizadores.
} 
a autonomia de organizações negras como possibilidades de desmantelamento do racismo institucional e ideológico constituído por essa articulação. Guardadas as especificidades quanto aos modelos de urbanização e padrões políticos e sociais, elucidar um modelo de interpretação da comunidade afrodescendente residente no Brasil poderia informar modelos interpretativos ou o aprimoramento dos já existentes, especialmente no que tange às dinâmicas de raça e gênero.

[...] a questão fundamental da natureza da colonização e do póscolonialismo enquanto categorias e práticas de contestação e mecanismos críticos para a constituição de identidades coletivas. (ALVA, 1994, p. 244, tradução nossa) $)^{8}$

De certo modo desenha-se uma possibilidade de compreender os espaços negros ${ }^{9}$ aqui descritos como de auto-organização dessa comunid ade e construção de articulações não apenas entre linguagem, políticas antirracistas e políticas de classe, mas sobretudo como esses elementos estão atravessados pela interseção entre gênero e raça, produzindo representação e atribuindo papéis específicos às mulheres negras e a seus projetos de vida individuais e coletivos. Ou seja, que para além de figurarem como espaços de sociabilidade e estabelecimentos de comunidades a partir do reconhecimento das barreiras construídas pelo racismo, clubes negros e bailes figuram como espaços de entrelaçamento e produção de sentidos particulares ao mesmo tempo que remetidos a modos de ser e estar da diáspora africana.

\footnotetext{
8 “[...] the fundamental question of the nature of colonialism and postcolonialism as categories/practices of contestation and as mechanisms critical to the constitution of new collective identities" (ALVA, 1994, p. 244).

${ }^{9}$ Inicialmente entendemos os espaços negros a partir de duas concepções: primeira, espaços negros permanentes seriam espaços físicos ocupados pela população negra e reconhecidos pela sociedade mais ampla como espacialidades organizadas e frequentadas, senão exclusivamente, majoritariamente por negros/as; por exemplos clubes e sociedades beneficentes negras. Clubes e sociedade foram considerados no momento da fundação como espaços de encontro de negros/as nas comunidades locais, como o bairro, a cidade e/ou as regiões circunvizinhas. Cabe destacar que esse espaço foi reconhecido, legitimado e afirmado como local de encontro e estabelecimento de relações políticas, sociais e culturais entre negros e negras. Enquanto em um primeiro exercício de reflexão a noção de espaço negro está circunscrita em um espaço físico determinado como um território ocupado por negros/as, há uma segunda dimensão do termo que se refere aos espaços negros ocasionais, como feiras negras, encontros, bailes black, bailes charme, bailes de samba-rock e rodas de samba. Nesses territórios configura-se a ocupação contextual, na maior parte das vezes para a realização dos eventos supracitados, o que transformaria espaços isentos da ocupação organizada de negros em territórios negros. Não seria, para tanto, a mobilidade dos espaços, mas dos sujeitos frequentadores que permitiria que o espaço viesse a ser considerado ocasional. Trata-se, por exemplo, de um baile black que ocorra em um clube militar, ou seja, o local é reconhecido como um espaço de socialização de militares, no entanto, naquele momento, recebe configuração e significado novos, transformando-se em um espaço de sociabilidade se não exclusivamente negro, regido pelas relações e dinâmicas da cultura negra.
} 


\section{Clubes sociais negros e bailes black/samba-rock}

O surgimento dos clubes sociais negros demonstra que o racismo se configurou de modo bastante específico a partir das dinâmicas históricas, políticas e sociais no contexto nacional. É sabido, por exemplo, que as formas de segregação impostas à América Latina se distinguiram das impostas aos Estados Unidos. ${ }^{10}$ Andrews (2007, p. 159) afirma que afrodescendentes prósperos no pós-abolição perceberam tal segregação e procuraram meios de integrar os espaços de sociabilidade típicos da classe média branca, buscando como estratégia a construção de espaços similares para uma parcela da população negra que estava, em sua maioria, entre a classe média branca e o proletariado negro (organizações sociais e cívicas paralelas às criadas pela classe médica branca).

Em uma economia em plena expansão, pautada pelas exportações e pelas ideologias do racismo científico, em voga desde o século XIX, instaurou-se uma situação bastante contraditória para a população afrodescendente que, em alguma medida, conseguia fazer parte do crescimento econômico da época. A mobilidade econômica não garantiu o acesso aos espaços típicos dos sujeitos que ascenderam socialmente. Negros e negras conviviam com a recusa à admissão de espaços da elite, como restaurantes, barbearias, hotéis e até mesmo estabelecimentos públicos, além dos clubes sociais e da discriminação no mercado de trabalho. Foi nesse contexto que diversos espaços de congregação entre negros surgiram, como se pode observar no levantamento produzido por Andrews (2007, p. I60-I6I):

Estas incluíam clubes sociais de elite, como El Progresso (Santiago, Cuba); Club Atenas (Havana), La Perla Negra (Santo Domingo), Kósmos (São Paulo) e outras, menos prestigiosas, porém mais numerosas, as "sociedades recreativas" (Cuba, Uruguai) e os "clubes de dança" (Brasil); associações atléticas como a Alianza Lima (Lima) e a Associação Atlética São Geraldo (São Paulo), que patrocinavam times de futebol, competições de corrida e outros eventos; e organizações cívicas como a Federação dos Homens de Cor e o Centro Cívico Palmares, no Brasil, e o Directorio Central de las Sociedades de Color em Cuba. No limite entre os níveis inferiores da classe média negra e os níveis superiores do proletariado negro estavam as sociedades de ajuda mútua, como o Centro de Cocheros (Havana), a Sociedade Protetora dos Desvalidos (Salvador) e La Protectora e o Centro Uruguay (Buenos Aires); e na Argentina, no Brasil, em Cuba e

\footnotetext{
10 Diferentemente dos Estados Unidos, durante o regime de segregação racial, em que as divisões pautadas na raça eram públicas e explícitas, o Brasil passou por intensos processos políticos que ora apontavam para o embranquecimento como alternativa para o processo de modernização nacional (vinda de imigrantes europeus e da ausência de políticas públicas destinadas aos negros), ora pautava-se na anulação do debate racial, considerando-se que este não se configurava como marcador dos processos de subalternização.
} 
no Uruguai (e talvez em outros países, onde a pesquisa extensiva sobre organizações negras da virada do século está por ser feita), uma ativa imprensa negra registrava as atividades desses grupos.

A interdição aos membros da "nova elite" de frequentarem os tradicionais espaços da "elite" ${ }^{11}$ bem como seu reduzido ou nulo acesso aos bens e serviços de responsabilidade do Estado são apontados como alguns dos principais motivos para a constituição de clubes e sociedade negras. Para além desse marcador, os clubes surgiam com o objetivo de angariar recursos para custear a alforria de negros escravizados, além de auxiliar nas despesas de funerais, na educação de seus associados e na defesa de seus direitos.

Os Clubes Sociais Negros são espaços associativos do grupo étnico afrobrasileiro, originários da necessidade de convívio social do grupo, voluntariamente constituído e com caráter beneficente, recreativo e cultural, desenvolvendo atividades num espaço físico próprio. (OLIVEIRA apud ESCOBAR, 2OIO, p. 6I)

Os espaços de atuação dos clubes indicam que muitas das suas iniciativas visavam minimizar a ausência do Estado no atendimento aos direitos básicos da população negra no período pré e pós-abolição. De acordo com Figueiredo (2002), os estudos brasileiros clássicos, como, por exemplo de Pierson e Azevedo (apud FIGUEIREDO, 2002), demonstraram que no Brasil só era possível ascender a partir da negação da identidade negra, da assimilação de valores e dos comportamentos brancos. A observação de Figueiredo contribui para a reflexão sobre os clubes também como espacialidades destinadas a uma parcela economicamente emergente da população negra em que traços de sociabilidade da população branca foram reproduzidos e associados a elementos negros a fim de legitimar um lugar de classe em detrimento inclusive de uma parcela da população empobrecida e marginalizada. De acordo com Giacomini (2006), ao refletir sobre as dinâmicas de sociabilidade do Clube Renascença, acessórios, calçados, penteados assim como posturas corporais estariam diretamente associados a uma posição social. Segundo a autora:

\footnotetext{
${ }^{11}$ Em uma economia em plena expansão, pautada nas exportações, as ideologias do racismo científico, em voga desde o século XIX, instauravam uma situação bastante contraditória para a população afrodescendente que, em alguma medida, conseguia fazer parte do crescimento econômico da época, porém lhes era negado o acesso aos espaços típicos dos sujeitos que ascenderam socialmente e conviviam com a recusa à admissão de espaços da elite, como restaurantes, barbearias, hotéis e até mesmo estabelecimentos públicos, além dos clubes sociais e do mercado de trabalho. Falar em elite negra requer atenção à medida que os grupos considerados de elite na comunidade negra não estavam equiparados com a elite branca no acesso a serviços, renda, escolarização e reconhecimento social. Propõe-se traçar um paralelo entre a elite negra e uma classe média branca, no que se relaciona a acesso a bens e serviços.
} 
Em outros termos, é como se o grupo reivindicasse que o critério de classe viesse a substituir o critério de cor (raça) no sistema classificatório [...] A a parência - o corpo - fala não somente das condições sociais, mas igualmente do espírito, da moralidade, indissociáveis da aparência. (GIACOMINI, 2006, p. 34-40)

Esse argumento orienta parte das investigações sobre as dinâmicas que distinguem os espaços de sociabilidade - grupos, organizações, bailes, clubes - do grupo negro e do grupo branco, considerando de antemão a persistência de determinados traços, mas também a particularidade de outros. De acordo com Gonçalves e Silva (2000, p. I39), "as organizações desempenham vários papéis no interior da população negra [...] se configuram como instâncias educativas, na medida em que os sujeitos que participam delas as transformam em espaços de educação política". Assim, o envolvimento dos clubes com a alfabetização de ex-escravos e a criação de espaços de sociabilidade para o fortalecimento da identidade negra demonstra a atuação dos grupos para além de suas atividades recreativas e culturais, na qualidade de atividades destituídas de ação política, mais também como modelos de associativismo com vistas ao enfrentamento e à superação do "lugar do negro".

Os clubes sociais, pensados como espaços de sociabilidade negra, por meio de bailes, reuniões, atividade educacionais e políticas, forjaram e forjam elementos essenciais para a cultura negra. Batista (2015, p. 19) destaca a "importância do lazer como umas das práticas herdadas da ancestralidade africana, em que há também um esforço em demonstrar que essas atividades acabaram por se tornar um importante veículo de sustentação emocional e psíquica para a sobrevivência grupal das populações negras".

De fato, clubes e bailes não estão dissociados na história da comunidade negra. Os clubes muitas vezes seguem nos registros históricos atrelados aos grandes bailes realizados em suas sedes sociais. Nesse sentido, é possível estabelecer a pluralização dos espaços e a alteração de algumas dinâmicas em relação aos bailes. Essa pluralização atualiza os sentidos desses eventos, sem, contudo, dissociá-los. A definição de baile que segue pensa o baile como uma reunião festiva, onde a finalidade central é a dança e a interação entre seus participantes: "Os bailes em salões de gafieiras, clubes sociais, dancing clubs e mesmo em casas de família figuram, na história do samba, como espaços e momentos não só de lazer e entretenimento, mas também de socialização e afirmação artística (LOPES; SIMAS, 20I5, p. 30).

A autonomia dos bailes black em relação aos clubes relaciona-se ainda com questões como a perda das sedes sociais devido a impasses administrativos, somadas ao distanciamento das diretorias das demandas e dinâmicas dos membros (antigos e novos). Esses elementos são listados como propulsores do enfraquecimento dos clubes como 
espaços primordiais para o estabelecimento da sociabilidade negra, especificamente da juventude negra. ${ }^{12}$ Assim, os clubes que se constituíram como espaços de sociabilidade demarcados em um espaço fixo foram paulatinamente convivendo, e em alguns momentos sobrepostos aos bailes realizados fora das suas sedes sociais. ${ }^{13}$

Os bailes black ou de samba-rock, em comparação com os realizados nas sedes dos clubes sociais negros, passaram a ocorrer em diversos espaços das cidades, tais como clubes militares, salões de festa e associações comerciais. O termo "baile black", no estado de São Paulo, origina-se a partir das equipes ${ }^{14}$ de show, como a Zimbabwe ${ }^{15}$ e a Chic Show $-{ }^{16}$ mantendo os exemplos no escopo do estado de São Paulo -, e engloba, para fins deste artigo, os chamados bailes nostalgia, bailes de charme e bailes de samba-rock. Os bailes nostalgia, para citar um tipo, concentram um público majoritariamente adulto, na faixa etária superior a 35 anos; por outro lado, os bailes de samba-rock, que executam o charme nos intervalos, atraem desde um público bastante jovem, ${ }^{17}$ na faixa etária de 18 anos, até pessoas de 50 anos. Essa alteração representa transformações significativas na dinâmica e na sociabilidade desenvolvida nos bailes; agora de caráter ocasional, contextual e circunscrito.

Á medida que os clubes se distanciam das demandas de uma nova juventude negra, tornam-se também restritivos à dinâmica de sociabilidade desse público. As diversas incursões etnográficas possibilitaram a observação de perfis distintos nos eventos dos clubes e nos bailes, a constante demanda dos clubes direcionada à presença dos jovens em suas sedes, e ainda falas que remetem a um passado em que seus principais dirigentes, hoje homens com mais de 40 anos, eram jovens adultos e participaram ativamente dos

\footnotetext{
12 Não posso deixar de mencionar outras expressões artísticas, musicais e estéticas que têm representado parte significativa dos espaços e das dinâmicas de sociabilidade da juventude negra contemporânea das grandes cidades: o rap, o hip hop e as batalhas de slan e encontros de poetas e poetisas negros e periféricos em sua maioria.

13 Para Tenório (2013, p. 108) "o baile é um momento de aprimorar-se, de aprender, de relembrar os passos com outros dançarinos, de apropriar-se da energia vital, que emana da pista de dança”.

${ }^{14}$ Em consonância, equipes de bailes, como a equipe Chic Show e Zimbabwue, transformaram-se em significativas referências para os bailes negros durante a década de 1960. Musicistas e suas bandas, como o maestro Érlon Chaves e a Banda Veneno, Simonal e Jorge Bem Jor, marcaram a época como importantes referências à comunidade afrodescendente. Sobre o tema ver a dissertação defendida por Felix (2000).

15 A Zimbabwe foi criada em 1975 por três jovens negros: Williams, Serafim e "Black". Frequentadores dos bailes do Clube Aristocrata, com a desistência dos organizadores do evento, foram convidados a fazê-lo. Williams afirma que ao tomar conhecimento das lutas contra o colonialismo que ocorriam na África, propôs, em forma de solidariedade, a alteração do nome da equipe de "A Pá do Soul" para "Zimbabwe. A equipe chegou a ter uma gravadora - Zimbabwe Records - e 43 artistas contratados e dois programas de rádio diários" (FELIX, 2000, p. 48).

${ }^{16}$ Segundo a pesquisa realizada por Felix (2000), a Chic Show foi fundada por Luiz Alberto Silva, o Luizão, em 1968. Luizão tinha muitos discos e um bom equipamento de som, fato que o fazia receber convites para animar festas e bailes. Com o aumento dos pedidos, Luizão percebeu a impossibilidade de manter a atividade de forma amadora e decidiu criar uma equipe de som. 0 nome escolhido foi Chi Show. O auge da equipe foi em 1975, quando organizou um baile para 16 mil pessoas na Sociedade Esportiva Palmeiras. A equipe organizou shows de artistas nacionais como Tim Maia, Gilberto Gil e Sandra de Sá, e internacionais como James Brown, Gloria Gaynor, Earth Wind \& Fire e Jimmy Bo Home (FELIX, 2000).

17 Durante as incursões etnográficas nos eventos de samba-rock na capital e no oeste paulista foi possível observar crianças sendo iniciadas na dança pelo adultos, assim como um número de jovens bastante expressivo. Particularmente as crianças demonstram grande habilidade e conhecimento do ritmo e dos passos da dança.
} 
eventos dos clubes. Esses elementos são hoje descritos como parte dos argumentos que influenciam no deslocamento dos grandes eventos realizados nas sedes sociais dos clubes para os bailes realizados em outros espaços.

Nos casos acompanhados pela incursão etnográfica realizada até o momento de elaboração deste artigo, o Clube Aristocrata, localizado na cidade de São Paulo, e o Grêmio Recreativo e Familiar Flor de Maio, ${ }^{18}$ localizado no município de São Carlos, interior do estado de São Paulo; bem como os bailes black que já compõem o hall da pesquisa (Ribeirão Preto, Piracicaba, Araras, São Carlos e São Paulo) e o II Encontro Samba-Rock Mulheres, realizado na cidade de São Paulo, observou-se a recorrência de um estilo específico de música e dança: o samba-rock.

O samba-rock ${ }^{19}$ foi criado a partir do samba, de ritmos norte-americanos como o jazz e o rock and roll e ritmos caribenhos como a salsa e o merengue. Segundo o Dicionário da história social do samba (LOPES; SIMAS, 2015, p. 270), o samba-rock é uma denominação atribuída, originada na cidade de São Paulo, ao "estilo de dança que misturava passos oriundos do rock, do samba e de ritmos caribenhos, como a rumba e a salsa", surgido na década de 1960. Dançarinos e dançarinas que aprenderam samba-rock nos antigos salões, com pais, mães, tias e irmãos, durante as reuniões familiares, encontraram na dança uma possibilidade de profissionalização e consequentemente uma alternativa para o ingresso no mercado de trabalho, ${ }^{20}$ enquanto para muitos outros a dança permanece como espaço de sociabilidade a partir do qual elementos da cultura expressiva negra transatlântica são realocados e traduzidos.

No caso do samba-rock, constata-se um intenso processo de "institucionalização" que impõe a transformação de movimentos por meio de metodologias, nomeação dos passos e cópia de passos originários de outros estilos musicais - por exemplo, o samba de gafieira ou

\footnotetext{
18 O reconhecimento do Flor de Maio como patrimônio material e cultural no nível municipal ocorreu em 2011, pelo então prefeito Oswaldo Barba. Naquela ocasião o Conselho Municipal de Defesa do Patrimônio Histórico e Artístico de São Carlos (COMDEPHAASC) considerou o clube como patrimônio histórico e cultural do município. O clube social negro de São Carlos foi o primeiro do estado a ser tombado. Em 2014, o Conselho de Defesa do Patrimônio Histórico, Arqueológico, Artístico e Turístico (CONDEPHAAT) aprovou por unanimidade a abertura de estudos para o tombamento do Flor de Maio e de outros dois clubes do interior do estado: o Clube 13 de Maio, localizado no município de Piracicaba, e o Clube Beneficente Cultural e Recreativo 28 de Setembro, no município de Jundiaí. Ver: <http://www.saocarlos.sp.gov.br/index.php/noticias-2011/160865-barba-anunciatombamento-do-flor-de-maio-unico-clube-social-negro-de-sao-carlos.html>,

<http://www.saci.ufscar.br/data/clipping/imagens/30233_00.jpg>. Acesso em: 30 ago. 2017.

${ }^{19}$ Segundo Oliveira (2008), existem versões sobre o surgimento do termo samba-rock por conta da ordem em que as músicas eram executadas nos bailes, alternando-se ora uma canção de rock, ora um samba. Assim, primeiramente se falou em "rocksamba", e até mesmo se utilizava apenas o termo "rock", para só depois se afirmar o nome "samba-rock". Expressões como "É bom esse rock?" ou "Você sabe dançar esse rock?", eram frequentemente utilizadas, mesmo que estivesse tocando no baile alguma música brasileira ou até mesmo um jazz norte-americano.

${ }^{20}$ Durante o Il Samba-Rock Mulheres, evento promovido por professoras de samba-rock da cidade de São Paulo, realizou-se uma roda de conversa com o tema "A profissionalização do samba-rock", entre outras questões foram elencadas estratégias de capacitação e gerenciamento para que a dança seja uma possibilidade de inserção no mercado de trabalho para inúmeras dançarinas que tiveram o contato com a dança nas relações familiares ou nos bailes de samba-rock.
} 
mesmo a zumba. Segundo algumas interlocutoras, professoras de dança de salão, e entre os estilos de samba-rock, a "institucionalização" da dança foi importante para que pudesse aspirar ao reconhecimento como dança de salão e ensinada em academias de dança. ${ }^{21}$

\section{Rainhas do clube e musas do samba-rock}

A presença das mulheres nos clubes sociais negros apoiou-se na valorização de certo modelo de feminilidade, o qual estava atrelado à representação de determinado modelo familiar segundo o qual caberia à mulher a garantia da ordem moral em que se pressupunha um afastamento da "baderna", do estereótipo da pobreza e da desordem atribuída às famílias negras. Essa preocupação pode ser observada a partir do modelo de feminilidade construído nos bailes e nos desfiles de miss. Coube às mulheres e meninas, filhas e esposas dos sócios e/ou fundadores dos clubes a centralidade em um processo de afirmação da mobilidade social desenvolvida pelos maridos e pais. Segundo Giacomini (2006), é recorrente a preocupação em demonstrar o fato de serem um grupo de famílias ou de indivíduos organizados familiarmente. Cabe aqui a inferência ao próprio nome do Grêmio Recreativo e Familiar Flor de Maio. ${ }^{22}$

Tendo a família como elemento de distinção, mulheres e adolescentes conviveram com alternativas específicas de trânsito em suas construções ou identificações de gênero, e consequentemente das performances de gênero e afetivo-sexuais. Os bailes de debutantes embalaram clubes como o Aristocrata (Figura I). ${ }^{23}$ Esses bailes contaram com preparações relacionadas à locação dos espaços mais privilegiados da cidade, buscando muitas vezes um evento associado aos padrões de vestimenta, de organização e de requinte dos clubes sociais mais renomados. A partir dos registros fotográficos utilizados como materiais de análise, observa-se o rigor nos trajes, tanto femininos quanto masculinos, a preocupação com a moralidade e a reprodução de padrões de classe até então apartados da população negra. É notória ainda a recorrência do uso de vestidos brancos alinhados, em sua grande maioria com cortes formais, poucos decotes ou quase nenhuma parte do corpo exposta. Os homens seguem a mesma linha de formalidade na orientação de suas vestimentas. Ou seja, a

\footnotetext{
${ }^{21}$ Atualmente a cidade de São Paulo reúne diversas academias de dança que oferecem aulas de samba-rock a um público que engloba o encontrado nos bailes black e em eventos realizados em clubes e sociedade negras, mas também para um outro público bastante distinto desse perfil. A mercantilização da dança por meio da inclusão nas academias promoveu consideráveis alterações tanto do público, visto que as aulas necessitam de investimentos financeiros, além de determinada organização cotidiana para a frequência das academias, quanto promoveu alterações nos espaços de execução dos movimentos e significativas mudanças nos próprios movimentos, visando, de acordo com algumas interlocutoras, à profissionalização da dança por meio da padronização do estilo.

${ }^{22}$ No caso do Grêmio Recreativo e Familiar Flor de Maio, a direção articulou a retirada do termo "Familiar" sob a alegação de que estaria nele vinculada a ideia de que o clube deveria arcar com auxílios financeiros, atividade que o clube não realizaria mais.

${ }^{23}$ O Clube Aristocrata tornou-se uma referência para a elite negra paulistana. Localizado na capital do estado de São Paulo, o clube teve entre seus participantes advogados, médicos etc. De acordo com seus fundadores, os membros do clube eram todos negros da alta sociedade.
} 
reprodução de padrões estéticos atribuídos à classe média branca. Contudo, no que diz respeito à moral, seu caráter mais restritivo recai sobre as mulheres. Considerando ainda os clubes como espaços de construção de laços afetivos voltados ao matrimônio e à manutenção da moral do grupo, recaí sobre as mulheres a garantia do status familiar e da formação e manutenção de alianças entre as famílias (GIACOMINI, 2006).

\section{Figura 1. Baile de Debutantes no Clube Aristocrata.}

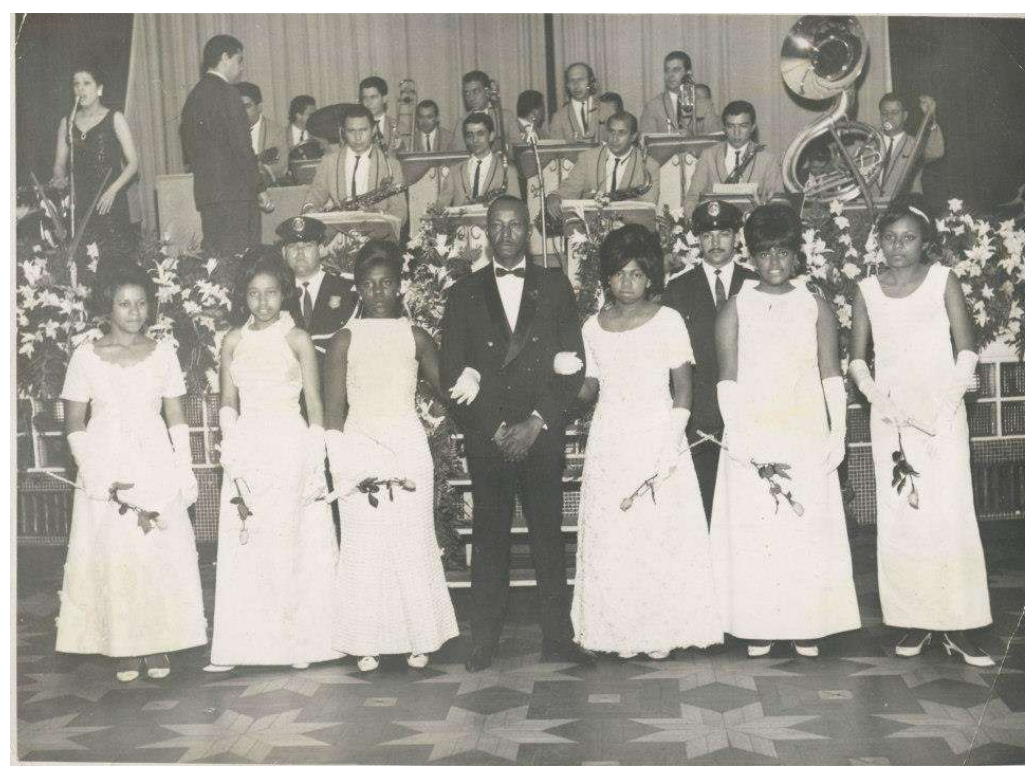

Fonte: Acervo Clube Aristocrata. Disponível em: <https://www.facebook.com/aristocrataclub>. Acesso em: 7 jul. 2017.

O investimento na imagem foi adotado como possibilidade de fugir do estigma da cor. Segundo Giacomini (2006), considerando a impossibilidade de alterar a cor, o efeito de deslocamento do olhar e da atenção para outros focos atuava como possibilidade de neutralização do estigma e da construção da aparência como possibilidade de intervenção na cor. A boa aparência exposta pelos cabelos sem referência à estética negra empobrecida, as roupas alvas, os comportamentos regrados e a moralidade buscavam o status, ou seja, a relevância da família dentro dos moldes da sociedade mais ampla, centrada principalmente nas representações de feminilidade e nas orientações afetivosexuais das mulheres e jovens negras.

Se por um lado a realização dos desfiles de miss poderia indicar certo nível de afrouxamento dos valores mais tradicionais atribuídos à feminilidade, por outro nota-se, com o apoio de autoras como Giacomini (2006), Escobar (2010) e Braga (2015), que a escolha das rainhas nos clubes e nas sociedades (Figura 2) atuou no estabelecimento e/ou manutenção do status social desses espaços em relação à reprodução do feminino como belo, elegante, educado, gentil, sensível e servil. 
[...] a questão do corpo estava absolutamente relacionada à moral, aos códigos de civilidade de uma época. O conceito de beleza reproduzido pelos tantos concursos, de tantas organizações, condizia com aquele conceito do qual já falava o século XVIII [...]: "que tem por característica fundamental não separar a beleza física das virtudes morais", de modo que a rainha era considerada porta-voz da associação que a elegia não apenas por motivos estéticos, mas, principalmente, por representar, ela mesma, os valores sociais pelos quais a própria associação almejava ser reconhecida. (BRAGA, 2015, p. 192)

Figura 2. Coroação da Rainha Black no Grêmio Familiar e Recreativo Flor de Maio.

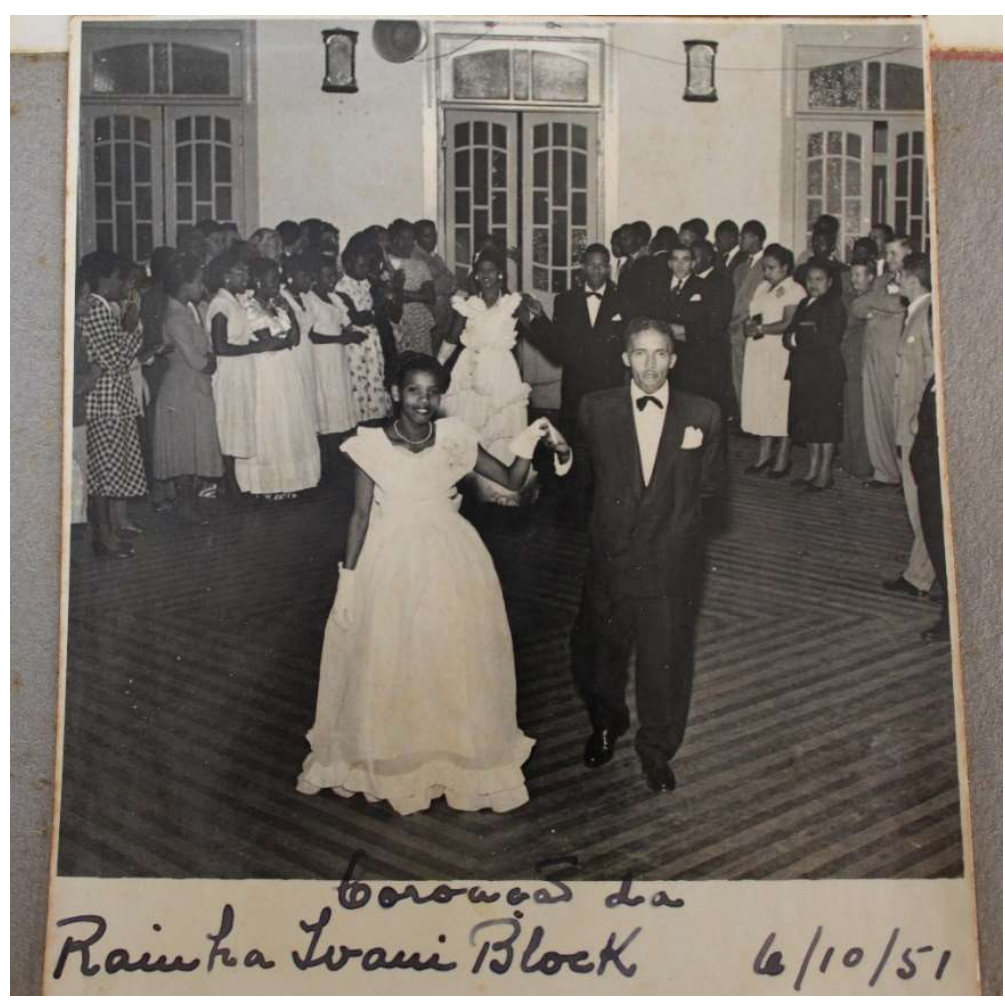

Fonte: Acervo da autora.

O que destacava as mulheres negras eleitas como miss era exatamente as características que lhes atribuíam as condutas e os valores das mulheres brancas, ou seja, novamente a valorização de um feminino gentil, dócil, educado, sensível, servil. A atribuição direta às mulheres estendia-se a suas famílias no que tange ao estabelecimento e à expressão da moral, das condutas e dos valores daquela sociedade. As mulheres são aqui, portanto, baluartes da moralidade. É importante afirmar que a constituição de uma sociabilidade negra não visa concretar e homogeneizar as distintas estratégias do grupo, considerando os contextos e as dinâmicas em que devem ser resguardadas as contradições internas e mesmo a busca por reproduções de padrões externos, pelos mais diversos fins.

Assim como os bailes de debutantes, a escolha das rainhas representou um espaço de construção de sociabilidade no interior dos clubes. Uma sociabilidade negra preocupada 
com a distinção desse grupo frente aos demais grupos negros da sociedade: os desagregados, marginalizados, empobrecidos e associados à imoralidade e à vagabundagem. Nas atividades desenvolvidas pelos clubes sociais negros, a beleza das mulheres excedia os limites de seus corpos, chegando aos preceitos ditados pela moral e pelos bons costumes, alçando o papel de boa esposa, boa mãe e dona de casa, e ainda os valores culturais que cultivava e fazia reverberar em defesa dos seus, em contraposição aos valores atrelados aos grupos negros que não frequentaram os espaços dos clubes (BRAGA, 2015). Ou seja, as representações de feminilidade e de raça encontram-se nas práticas e nas condutas das mulheres negras na busca pela consolidação da distinção social para além da pertença racial.

Para além dos pontos supracitados, a configuração dos espaços decisórios de clubes e sociedades - a presidência, as diretorias e as secretarias -, majoritariamente ocupados por homens, contribui para a validação dos argumentos apresentados até este momento. Em suas análises sobre o Clube Treze de Maio, com sede na cidade de Santa Maria (RS), Escobar e Moraes (2016, p. I23) elucidam o papel e a representação delegados às mulheres no interior da associação:

Em relação às mulheres negras, a tradição seletiva se forma no plano da moral, pois não era "qualquer mulher negra" que poderia frequentar o Clube Treze de Maio. Além das relações de poder legitimadas pelo crivo do homem negro, isto é, os dirigentes (sempre homens) que definiam quem podia ou não permanecer dentro do clube, elas precisavam também passar pelo "olhar" das mulheres bem casadas ou moças "que não se perderam" para poder ali frequentar. Ou seja, o clube não admitia em seus quadros mulheres separadas, viúvas, mães solteiras ou aquelas viviam junto aos seus companheiros fora do casamento.

Clubes e associações, principalmente nos eventos em que as mulheres desempenhavam um papel central, pautaram-se na construção de um "feminino desejável", conformado a partir da definição dos papéis de gênero submersos em um modelo de socialização pautado em valores familiares ocidentais em que havia quase nenhum espaço para transgressão ou trânsito de normas. De acordo com Amâncio (1994 apud ESCOBAR; MORAES, 20I6), havia no clube a ambiência para a cristalização de tradições seletivas que associavam papéis sociais a cada um dos sexos, determinando as diferenças no comportamento de homens e de mulheres.

Observações atuais sobre o Clube Aristocrata indicam que o padrão de sociabilidade pautado no gênero não foi, ao menos naquele espaço, totalmente transformado. Mesmo tendo em seu quadro de presidência duas mulheres, eventos atuais do clube distinguem em sua dinâmica os locais a serem ocupados pelas mulheres e os locais ocupados pelos homens. 
No entanto é fato que também coube às mulheres outras atividades que tecem, de modo quase invisível, a sociabilidade entre os membros do clube. Segundo Félix (2000, p. 158),

Estudos recentes apontam a presença da mulher negra exercendo atividades de educadora, auxiliando atividades de escritório, atuando na manutenção e limpeza dos recintos, cantando, dançando, atuando como garçonetes nos recintos que recebiam os frequentadores em atividades de "preparo" ou "finalização" do visual para a entrada devida ao recinto. A efetiva presença vem sendo ratificada através do testemunho destas protagonistas confirmado pela documentação registrada nos arquivos dos clubes sociais às quais pertencem.

Em certa medida esse padrão moral permanece nos eventos realizados nos clubes e nos bailes black, mesmo quando ocorrem fora dos clubes sociais. Essa afirmação é constatada pelas incursões realizadas nos clubes e bailes. Quando se trata dos bailes, e especialmente dos bailes black de samba-rock na capital e no interior do estado de São Paulo, a cultura ${ }^{24}$ samba-rock ganha então novos e importantes contornos. A inclusão do samba-rock ${ }^{25}$ como dança de salão e, consequentemente, sua inserção nas academias de dança têm contribuído para a formatação de novos cenários no que se refere ao papel e à representatividade das mulheres negras.

A preocupação com a moralidade, com a garantia do baile como um espaço de estabelecimento de relações valoradas socialmente, é mantida. As regras em torno das vestimentas dão base para essa afirmação, mesmo com a transformação de padrões. Ainda assim, hoje é possível observar mulheres com roupas coloridas, decotes, roupas mais curtas, o que se contrapõem com os cartazes de divulgação dos bailes. Aqui cabe um importante destaque, a depender do perfil do evento, o padrão estético segue os mesmos padrões dos eventos realizados nos clubes sociais. Em alguns bailes foi possível observar vestimentas coloquiais, enquanto em outros isso não se reproduziu. O padrão de vestimenta interliga-se ao perfil do evento, definido pelo perfil de seus organizadores, pelo vínculo do evento com a tradição festiva do local onde se realiza e, por fim, ao local de realização do evento. Os bailes que compõem a Festa do $\mathrm{Carmo}^{26}$ são exemplos ilustrativos dessa observação.

\footnotetext{
${ }^{24}$ A obra O atlântico negro (2012), de Paul Gilroy, é indicada como referência na compreensão da cultura da diáspora africana constituída politicamente por meio da música.

25 No dia 30 de agosto é comemorado no estado de São Paulo o dia do samba-rock. Segundo fontes jornalísticas e interlocutores/as da pesquisa, a data escolhida homenageia Jackson do Pandeiro, o primeiro músico a usar a palavra "sambarock" em uma canção ("Chiclete com banana", 1958), e um dos grandes nomes da música brasileira. No mês de agosto ocorrem diversos eventos em comemoração ao dia do samba-rock, merece destaque o Encontro de Samba-rock, que ocorre anualmente em agosto na cidade de Campinas, reunindo dançarinos, professores, equipes de dança e amantes do samba-rock durante 12 horas de festa. Disponível em: <https://tvbrasil.ebc.com.br/reportersaopaulo/episodio/dia-31-de-agosto-foi-comemorado-odia-do-samba-rock-no-estado-de-sao-paulo>. Acesso em: 30 maio 2020;

e <https://www.bol.uol.com.br/entretenimento/2016/11/03/samba-rock.htm>. Acesso em: 30 maio 2020.

${ }^{26}$ A Festa do Carmo é considerada um dos eventos que marcam a luta e a resistência da população negra no interior do estado de São Paulo. Em 2018 a festa completou 130 anos. Dentre suas atividades, que duram cinco dias, estão eventos de futebol, baile
} 
O tradicional baile de gala segue à risca a orientação de vestimenta. Só é possível adentrar no espaço do baile com trajes de gala. A seguir descrevo parte das anotações de campo, colhidas durante a etnografia no referido baile.

Enquanto aguardava na fila para entrar no baile, uma mulher disposta logo atrás de mim mostrava apreensão com a possibilidade de ser barrada na entrada por estar vestindo um longuete (um modelo de vestido que possui o seu comprimento abaixo dos joelhos, porém não chega a ser comprido até os pés, o que impede que seja categorizado como traje de gala). Durante o tempo em que realizava a compra dos ingressos assisti a mulher ser impedida de entrar. Houve insistência por parte dela, responsáveis pelo evento foram chamados para solucionar o caso, no entanto não houve alternativa. A entrada seria autorizada apenas com a alteração da vestimenta. (Anotação da autora, 20I7)

A Figura 3 é um registro realizado no baile mencionado. Nele pode-se observar, além da execução de passos do charme, mulheres vestidas com roupas de gala, traje definido por vestido longo e sapatos de salto alto.

Figura 3. Baile de gala da Festa do Carmo (Araraquara/SP).

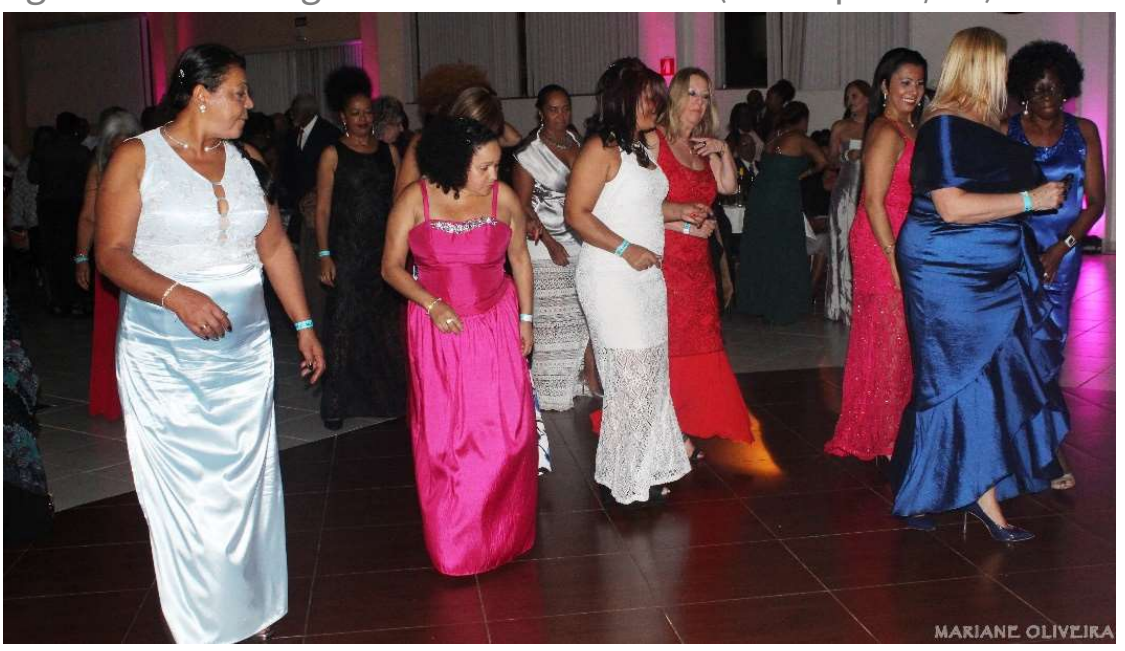

Foto: Mariane Oliveira (2017). Acervo da autora.

O traje de gala foi exclusividade do baile citado. Nos demais, em geral exige-se o traje esporte fino, quase unânime entre as referências de vestimenta dos bailes black/nostalgia atuais. Nos bailes de samba-rock essa referência está menos presente. Nos eventos da capital de São Paulo houve transformações quanto aos padrões esperados para o baile. $O$ esporte fino foi substituído por trajes que fazem referência a estilos de vestimenta associados aos negros norte-americanos.

de samba-rock, feijoada e baile de gala. Também compõe o evento uma feira popular. A Festa do Carmo foi tema da pesquisa realizada por Valquíria Pereira Tenório intitulada "Baile do Carmo": memórias, sociabilidade e identidade étnico-racial em Araraquara (2013). 
Além da preocupação com a vestimenta, as condutas orientam-se sempre por comportamentos coadunados com a moralidade e os valores familiares. Cenas explicitas de casais enamorados são raras. Atenta-se para a dança e para os códigos de paquera quase que imperceptíveis, que se traçam antes do convite para a dança, durante a dança e, quando bem-sucedidos, prosseguem. A discrição na formação dos casais foi observada também durante as aulas semanais de samba-rock que acontecem na sede do Flor de Maio.

Logo o baile permanece como um importante espaço para o estabelecimento de vínculos afetivos e matrimoniais, agora menos intenso no que tange à manutenção do status das famílias e mais relacionado com a construção de um espaço de pertença e reconhecimento intragrupo. Ressalta-se como uma das possibilidades de investigação os debates sobre solidão e instabilidade nos relacionamentos amorosos sobre os quais as mulheres negras estão mais expostas. O baile mantém-se, portanto, como espaço de compartilhamento de um modelo de sociabilidade e de reconhecimento de um lugar onde, potencialmente, os registros da ancestralidade e da exclusão possam ser compreendidos e compartilhados. O feminino aqui tem se mostrado menos atrelado às imagens da docilidade, da gentileza ou da reprodução de papéis como boa mãe e a boa esposa sem, contudo, deixar de reproduzir o machismo, como visto no próximo parágrafo.

O Samba-Rock Mulheres é um evento voltado exclusivamente para mulheres, tendo sido observado por mim em 20I7, em sua terceira edição (Figura 4 ). ${ }^{27} \mathrm{O}$ evento ocorre até o ano de 2020, e de acordo com uma das suas organizadoras e idealizadoras, o SambaRock Mulheres surgiu em oposição a um estilo de samba-rock bastante difundido na capital de São Paulo, o samba-rock nó. Nesse estilo o cavalheiro é responsável por praticamente todos os passos, e a dança tem por objetivo principal apresentar ao público enlaces mais complexos. Na medida em que o dançarino consegue tornar mais complexos os enlaces entre braços, pernas e troncos durante a condução de sua parceira de dança, este passa a ter um maior reconhecimento entre seus pares.

\footnotetext{
${ }^{27}$ A primeira edição foi realizada em 2016; a segunda, no início de 2017; e a terceira, em julho do mesmo ano. Diferentemente das edições anteriores, a terceira edição contou com a presença de dançarinos e dançarinas, com o objetivo de aproximar o diálogo sobre a condução de suas parceiras.
} 
Figura 4. Material de divulgação da segunda edição Samba-Rock Mulheres (2017).

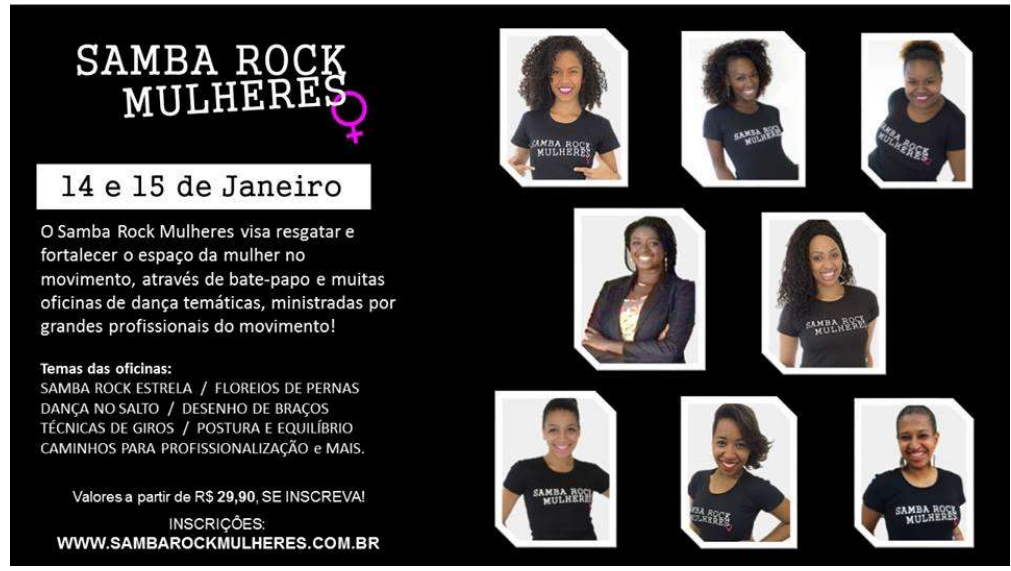

Fonte: Acervo da autora.

O samba-rock nó tem sofrido sérias críticas, e o evento Samba-Rock Mulheres surge exatamente nesse escopo. Para suas idealizadoras, o novo estilo impede que a dama realize quaisquer movimentos e dá exclusividade às habilidades masculinas. Durante a terceira edição do evento, em 20I7, houve uma roda de conversa intitulada "Lugar da mulher no Samba-Rock", na qual as participantes do evento, incentivadas pelas idealizadoras, se expressaram sobre o papel secundário que vinham desenvolvendo no samba-rock como dançarinas e a dificuldade de superar esse lugar em relação a seus parceiros. Tanto as participantes como as idealizadoras do evento apresentaram sucessivas críticas à presença e ao reconhecimento secundário das dançarinas no samba-rock, justificando a construção do evento como uma articulação contrária a tais práticas.

\section{Considerações finais}

Por meio desta pesquisa pude observar uma valorização das mulheres negras instituída a partir da dança. Nos salões as dançarinas mais habilidosas disputam a atenção dos presentes e são valorizas, em geral, por suas habilidades. A dança, para Magnani (apud TENÓRIO, 2OI3, p. IO8), "constrói um espaço concreto e palpável de afirmação”. Quando entendemos a dança como um elemento de trânsito entre corpo e ancestralidade, assim como Santos (2002), em que se elabora uma síntese das tradições familiares expressas na conexão entre a comunidade africana e a comunidade negra, a dança passa a ser vivida como um meio de expressão e síntese de experiências empíricas, intelectuais, emocionais e espirituais que resultam de modo vital e dinâmico nas atividades corporais. Assim, "a dança integra o físico, o psíquico, o intelecto e o emocional [...]. No que tange à sociedade, a dança tem tido o poder de reforçar a importância do corpo como instrumento e símbolo de poder. Tem também revigorado um conjunto de valores e crenças” (SANTOS, 2002, p. 2I). 
Retomamos a reflexão de Giacomini (2006) para destacar a centralidade do corpo nessas experiências. Segundo a autora "o corpo se impõe como um dos lugares privilegiados de inscrição da identidade" (p. 35). As transformações nas inscrições dessa identidade, hoje marcadas por uma valorização dos elementos africanos, em detrimento do passado, inscreve nos novos corpos os elementos simbólicos da ancestralidade africana remodelada como afro-brasileira. Além das estampas, das cores, das figuras geométricas, dos turbantes, dos colares volumosos, os cabelos são os elementos mais recorrentes na referência da expressão cultural do atlântico negro.

As contribuições desses espaços para os processos de identificação dão ênfase aos processos de subjetivação das várias identificações passíveis de serem atribuídas ou adotadas pelo sujeito em meio social (HALL, 2005). Segundo Hall (2005, p. 38), "a identidade é realmente algo formado, ao longo do tempo, através de processos inconscientes, e não algo inato, existente na consciência no momento do nascimento", assim, o clube circunscrito em sua sede demarca um espaço tanto geográfico quanto simbólico de reconhecimento e afirmação para a comunidade negra.

As estratégias de sociabilidade adotadas nos bailes, a representação que o estilo de dança, no caso do estado de São Paulo, do samba-rock e as transformações estéticas e artísticas do ritmo musical e dos passos, considerando-se tanto os bailes como a profissionalização do ritmo musical e da dança, expressam uma tríade em que a sociabilidade, a música e a dança delineiam uma centralidade investigativa sobre a comunidade afrodescendente no que confere a suas dinâmicas e modelos de socialização impressos nesse e por esse grupo.

Os integrantes dos clubes não buscavam apenas a formação de espaços próprios de socialização, mas também o reconhecimento como membros integrais da nação. Para tanto era preciso ajustar os aspectos passíveis de negociação. Daí nossa afirmação de que nesses locais, muito mais do que o corpo, as práticas realizadas a partir do corpo abriram espaços de negociação em que as mulheres negras ocuparam e permanecem ocupando lugares centrais, mesmo que aparentemente marginalizados, entre os anseios de reconhecimento pela sociedade brasileira e os elementos de uma cultura negra transnacional.

O corpo, e particularmente os corpos das mulheres negras, passou então a apresentarse como um espaço sóbrio, formal e correspondendo aos padrões valorativos e morais das sociedades de sua época. Essa fala se apresenta no plural, pois compreende que em certa medida essas práticas foram constantemente reinseridas e seguem até a atualidade. A noção dos estereótipos negativos atrelados à população negra não era desejada pelos membros dos clubes, pelo contrário, havia um interesse em demonstrar seu distanciamento, daí a importância da regulação das práticas, das ações e das relações estabelecidas com e pelas mulheres negras no interior dos clubes. Assim, conclui-se que a normalização das 
representações das mulheres negras foi uma entre as ações possíveis. Por outro lado, aspectos positivos não foram apagados, como, por exemplo, a capacidade de realização de eventos e as habilidades musicais; aspectos a partir dos quais podemos hoje reconstruir algumas rotas para o estabelecimento de redes de sociabilidades transatlânticas.

\section{Referências}

AGUIAR, M. M. Os clubes negros e seu papel na constituição da identidade e movimento negro: a história do Grêmio Recreativo e Familiar Flor de Maio em São Carlos-SP. InterAÇÕES - Cultura e Comunidade, v. 2, n. 2, p. 9I-IO5, 2007.

ALVA, J. J. K. The poscolonization of the (latin) americam experience: a reconsideration of "colonialism", "postcolonialism", and "mestizaje". In: After colonialism: imperial histories and postcolonial displacements. Princeton, New Jersey: Princeton University Press, 1994. cap. 9.

ANDREWS, G. "Uma transfusão de sangue melhor": o branqueamento, I880-1930. América Afro-Latina:I80o-2000. São Paulo: EDUFSCar, 2007. p. 15I-I86.

BATISTA, R. de C. S. Clubes negros na espacialidade urbana de Juiz de Fora. 20I5. Tese (Doutorado em Educação) - Programa de Pós-graduação em Educação Brasileira, Universidade Federal do Ceará, Fortaleza, 2015.

BENJAMIN, W. Experiência e pobreza e o narrador. Considerações sobre a obra de Nikolai Leskov. In: Obras escolhidas. Magia e técnica, arte e política. São Paulo: Brasiliense, 1994 .

BRAGA, A. História da beleza negra no Brasil. Discursos, corpos e práticas. São Carlos: EDUFSCar, 2015.

BRASIL. Constituição (1988). Constituição da República Federativa do Brasil. Brasília, DF: Senado Federal: 1988.

BRASIL. Edital de mapeamento dos clubes sociais negros. Disponível em: $<$ http://www.brasil.gov.br/cultura/20I4/o3/clubes-sociais-negros-serao-mapeadosem-todo-o-pais $>$. Acesso em: 3I ago. 2015.

D'ALLEVEDO, P. T. 1958, Ano que não terminou. Memória e performance na cena do baile black nostalgia paulistano. 20I7. Tese - Programa de Pós-graduação em Sociologia, Universidade Federal da Paraíba, João Pessoa, 2017.

ESCOBAR, G. Clubes sociais negros: lugares de memória, resistência negra, patrimônio e potencial. 20I0. 205 f. Dissertação (Mestrado em Patrimônio Cultural) - Programa de Pós-graduação Profissionalizante em Patrimônio Cultural, Universidade Federal de Santa Maria, Santa Maria, 2oIo. 
ESCOBAR, G. V.; MORAES, A. L. C. A mulher negra no interior de um clube social negro: a festa como lugar de sociabilidade, rigidez, moralidade e relações de poder. In: CONGRESSO INTERNACIONAL EM ESTUDOS CULTURAIS: GÉNERO, DIREITOS HUMANOS E ATIVISMOS, 5., 20I6. Estudo apresentado no Grupo de Trabalho "Usos do corpo; comportamentos e quotidianos pós-género como estratégias de agenciamento", 2016.

FELIX, J. B. de J. Chic Show e Zimbabwe e a construção da identidade nos bailes black paulistanos. 200o. Dissertação (Mestrado em Antropologia) - Programa de Pós-graduação em Antropologia Social, Universidade de São Paulo, 2000, São Paulo.

FIGUEIREDO, A. Novas elites de cor: estudos sobre os profissionais liberais negros de Salvador. São Paulo: Annablume, 2002.

GIACOMINI, S. M. A alma da festa. Família, etnicidade e projetos num clube social da Zona Norte do Rio de Janeiro. O Renascença Clube. Belo Horizonte; Rio de Janeiro: Editora UFMG; IUPERJ, 2006.

GILROY, P. Oatlântico negro. São Paulo: Editora 34, 2012.

GILROY, P. There ain't no black in the Union Jack: the cultural politics of race and nation. Chicago: The University of Chicago Press, 2002.

GONÇALVES, L.; SILVA, P. Movimento negro e educação. Revista Brasileira de Educação. Rio de Janeiro, n. I5, p. I34-158, dez. 2000.

GUSMÃO, N. M.; SIMSON, O. R. M. A criação cultural na diáspora e o exercício da resistência inteligente. Ciências Sociais Hoje: Anuário de Antropologia, Política e Sociologia, São Paulo, Vértice/ANPOCS, 1989.

HALL, S. A identidade cultural na pós-modernidade. Io. ed. Rio de Janeiro: DP\&A, 2005.

HALL, S. Pensando a diáspora: reflexões sobre a terra no exterior. In: SOVIK, L. (Org.). Da diáspora: identidades e mediações culturais. Tradução Adelaine La Guardia Resende. Belo Horizonte: Editora UFMG, 2006. p. 25-48.

LOPES, N.; SIMAS, L. A. Dicionário da história social do samba. Rio de Janeiro: Civilização Brasileira, 2015.

OLIVEIRA, L. X. O swing do samba: uma compreensão do gênero do samba-rock a partir da obra de Jorge Ben Jor. 2008. Dissertação (Comunicação) - Programa de Comunicação e Cultura Contemporâneas, Universidade Federal da Bahia, Salvador, 2008.

PAREKH, B. Rething multiculturalism: cultural diversity and political theory. Cambridge; Massachusetts: Harvard University Press, 2002.

ROLNIK, R. Territórios negros nas cidades brasileiras (etnicidade e cidade em São Paulo e Rio de Janeiro). Revista de Estudos Afro-Asiáticos I7-CEAA, Universidade Cândido Mendes, set. 1898. 
SANTOS, I. F. Corpo e ancestralidade: uma proposta pluricultural de dança-arte-educação. Salvador: EDUFBA, 2002.

SILVA, F. Os negros, a constituição de espaços para os seus e o entrelaçamento desses espaços: associações e identidades negras em Pelotas (I82O-I943). 2011.228 f. Dissertação (Mestrado em História) - Faculdade de Filosofia e Ciências Humanas, Pós-graduação em História, Pontifícia Universidade Católica do Rio Grande do Sul, Porto Alegre, 20II. TENÓRIO, V. "Baile do Carmo": memória, sociabilidade e identidade étnico-racial em Araraquara. Belo Horizonte: Nandyala, 2013. 